Macht und Ohnmacht der Zensur 


\author{
Hans Jörg Neuschäfer
}

\title{
MACHT UND OHNMACHT DER ZENSUR
}

Literatur, Theater und Film in Spanien (1933-1976)

J. B. Metzlersche Verlagsbuchhandlung Stuttgart 


\section{CIP-Titelaufnahme der Deutschen Bibliothek}

Neuschäfer, Hans-Jörg:

Macht und Ohnmacht der Zensur: Literatur, Theater und Film

in Spanien (1933-1976) / Hans-Jörg Neuschäfer. - Stuttgart:

Metzler, 1991

ISBN 978-3-476-00739-1

ISBN 978-3-476-00739-1

ISBN 978-3-476-03343-7 (eBook)

DOI 10.1007/978-3-476-03343-7

Dieses Werk einschließlich aller seiner Teile ist urheberrechtlich geschützt. Jede Verwertung außerhalb der engen Grenzen des Urheberrechtsgesetzes ist ohne Zustimmung des Verlages unzulässig und strafbar. Das gilt insbesondere für Vervielfältigungen, Übersetzungen, Mikroverfilmungen und die Einspeicherung und Verarbeitung in elektronischen Systemen.

(C) 1991 Springer-Verlag GmbH Deutschland

Ursprünglich erschienen bei J. B. Metzlersche Verlagsbuchhandlung und Carl Ernst Poeschel Verlag GmbH in Stuttgart 1991 


\title{
Inhaltsverzeichnis
}

\author{
TEIL I: VORAUSSETZUNGEN \\ Seite 1
}

1. Kapitel

Einleitung. Worum es geht. 1

2. Kapitel

Mythen vom Ewigen Spanien - aufgedeckt.

Warum mit Lorca begonnen werden muß. 10

Bodas de sangre (1933).

Das Schweigegebot und die Eruption der unterdrückten Gefühle. 11

Lorcas weitere Dramenproduktion.

Die beherrschende Rolle der «opinión». 27

Das Bernarda Alba-Syndrom (1936).

Oder: Das vorwegphantasierte Zensursystem. 31

\author{
3. Kapitel \\ Spanische Zensur. \\ Grundlagen und Auswirkungen. \\ Voraussetzungen zum Verständnis einer Epoche. 38 \\ Das Zensursystem (1936-1976) 39 \\ Der Diskurs der Zensur 47 \\ In Rätseln sprechen: Zensur als Kommunikationshemmung. \\ Das Symbol des isolierten Hauses. 49 \\ Zensur und Kreativität. \\ Beispiele einer paradoxalen Beziehung. 64 \\ Die Allgegenwärtigkeit der Zensur. \\ Nachwirkungen nach 1976.69
}




\section{TEIL II: ANWENDUNGEN}

Seite 77

4. Kapitel

Der Roman als Mittel der Identitätssuche.

Was war Spanien und was wird aus ihm werden? $\quad 77$

Camilo José Cela und La familia de Pascual Duarte (1942).

Oder: Zweideutigkeiten über das Landleben. 79

Miguel Delibes: Cinco horas con Mario (1966).

Oder: Wie Carmen die «apertura» sieht. 89

Juan Goytisolo: Señas de identidad (1966).

Oder: Spaniens Wandel aus der Sicht des Exils. 101

\section{Kapitel}

Die Bühne als Ort oppositioneller Verständigung. 124

Buero Vallejo und die Historie.

Das aktuelle Spanien im Spiegel der Geschichte. 125

Historia de una escalera (1949) 126

La doble historia del Dr. Valmy (1964/76) 139

El sueño de la razón (1970) 146

Sastre und die Inszenierung der Rebellion.

Klassikeradaptation und Gegenwartsdiagnose. 153

Guillermo Tell tiene los ojos tristes (1955) 154

La cornada (1960) 169 


\section{Kapitel}

Auf dem Weg zu einer anderen Mentalität.

Ansichten des Wandels im spanischen Film. 182

Berlangas Komödien und die Parodie spanischen «Brauchtums» 183

Bienvenido Mr. Marshall (1952/53) 184

El verdugo (1963) 196

Buñuels «spanische» Filme und das Gespenst der Emanzipation. 206

$$
\text { Viridiana (1961) } 207
$$

Tristana bei Benito Pérez Galdós (1892)

und bei Luis Buñuel (1970) 221

Sauras «Kinderfilme» und die «transición»

in eine neue Epoche. 232

La prima Angélica (1973/74) 233

Cria Cuervos (1976) 251

TEIL III: ZURÜCK IN DIE ZUKUNFT

Seite 275

7. Kapitel

Juan de Mairena (1936) und die Utopie einer spanischen Demokratie.

Warum dieses Buch mit Machado enden muß. 275 


\title{
TEIL IV: ANHANG
}

Seite 293

\author{
8. Kapitel \\ Zensurdokumente 293 \\ Übersetzung spanischer Zitate 327
}

Autorenportraits 334 